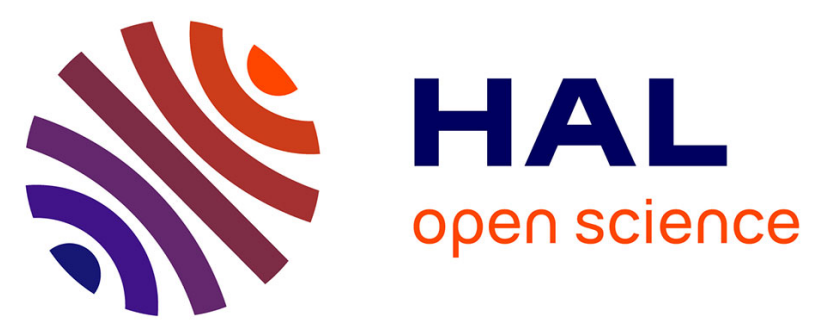

\title{
Virus mediated trophic interactions between aphids and their natural enemies
}

Corentin Dupont, Alexandra Michiels, Corentin Sochard, Nathalie Dardenne, Sophie Meyer, Veronique V. Brault, Yannick Outreman, Arnaud Sentis

\section{- To cite this version:}

Corentin Dupont, Alexandra Michiels, Corentin Sochard, Nathalie Dardenne, Sophie Meyer, et al.. Virus mediated trophic interactions between aphids and their natural enemies. Oikos, 2020, 129 (2), pp.274-282. 10.1111/oik.06868] . hal-02371815

HAL Id: hal-02371815

https://institut-agro-rennes-angers.hal.science/hal-02371815

Submitted on 20 Nov 2019

HAL is a multi-disciplinary open access archive for the deposit and dissemination of scientific research documents, whether they are published or not. The documents may come from teaching and research institutions in France or abroad, or from public or private research centers.
L'archive ouverte pluridisciplinaire HAL, est destinée au dépôt et à la diffusion de documents scientifiques de niveau recherche, publiés ou non, émanant des établissements d'enseignement et de recherche français ou étrangers, des laboratoires publics ou privés.

\section{(ㅇ)(1) $\$$}

Distributed under a Creative Commons Attribution - NonCommercial - NoDerivatives| 4.0 


\section{Virus mediated trophic interactions between aphids and their natural enemies}

Corentin Dupont ${ }^{3}$, Alexandra Michiels ${ }^{1}$, Corentin Sochard ${ }^{3}$, Nathalie Dardenne ${ }^{1}$, Sophie Meyer $^{4}$, Véronique Brault ${ }^{4}$, Yannick Outreman ${ }^{3}$ and Arnaud Sentis ${ }^{1,2}$

${ }^{1}$ UMR 5174; EDB (Laboratoire Évolution and Diversité Biologique); CNRS, Université Toulouse III, IRD, 118 route de Narbonne, FR-31062 Toulouse Cedex 9, France ${ }^{2}$ IRSTEA, Aix Marseille Univ., UMR RECOVER, 3275 route Cézanne, FR-13182 Aixen-Provence, France

${ }^{3}$ IGEPP, Agrocampus Ouest, INRA, Univ. de Rennes, Univ. Bretagne-Loire, Rennes, France

${ }^{4}$ UMR SVQV, INRA, Univ. de Strasbourg, Colmar, France

Corresponding author: Arnaud Sentis, UMR 5174; EDB (Laboratoire Évolution and Diversité Biologique); CNRS, Université Toulouse III, IRD, 118 route de Narbonne, FR-31062 Toulouse Cedex 9, France. E-mail: arnaud.sentis@ irstea.fr

Decision date: 05-Nov-2019

This article has been accepted for publication and undergone full peer review but has not been through the copyediting, typesetting, pagination and proofreading process, which may lead to differences between this version and the Version of Record. Please cite this article as doi: [10.1111/oik.06868]. 


\section{Abstract}

Microbial endosymbionts alter the phenotype of their host which may have cascading effects at both population and community levels. However, we currently lack information on whether the effects of viruses on both host phenotypic traits and host population demography can modify interactions with upper trophic levels. To fill this gap, we investigated whether a prevalent densovirus infecting the aphid Myzus persicae (i.e. MpDNV) can modify trophic interactions between host aphids and their natural enemies (i.e. predators and parasitoids) by influencing aphid phenotypic traits (i.e. body mass and defensive behaviours), population demography (i.e. density and age-structure) and susceptibility towards both predation and parasitism. We found that the virus decreased aphid body mass but did not influence their behavioural defences. At the population level, the virus had a minor effect on aphid adult mortality whereas it strongly reduced the density of nymphs and influenced the stage structure of aphid populations. In addition, the virus enhanced the susceptibility of aphids to parasitism regardless of the parasitoid species. Predation rate on adult aphids was not influenced by the virus but ladybeetle predators strongly decreased the number of aphid nymphs, especially for uninfected ones compared to infected ones. As a result, the virus decreased predator effect on aphid populations. By reducing both aphid quality and availability, increasing their susceptibility to parasitism, and modulating predator effect on aphid populations, we highlighted that viral endosymbionts can be prevalent drivers of their host ecology as they modify their phenotypes and interspecific interactions. These virus-mediated ecological effects may have consequences on enemies foraging strategies as well as trophic webs dynamics and structure.

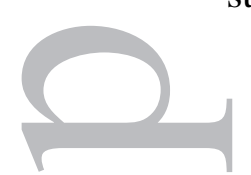

Keywords: densovirus infection, natural enemies' susceptibility, life-history traits, behavioural defences, physiological costs 


\section{Introduction}

Microbial symbionts can profoundly modify the ecology and evolution of host species and, by extent, the interactions between species within trophic webs (Kooi et al. 2004, Frago et al. 2012). In insects, bacterial symbionts can induce variation in the nutritional quality and availability of their hosts which can affect foraging strategies and intake rate by natural enemies (see Monticelli et al. 2019). By extent, symbiotic bacteria can indirectly influence both the structure and dynamics of food webs (e.g. Hrček et al. 2016, McLean et al. 2016, McLean 2019). Similar to bacterial endosymbionts, insects can also host viruses that can be transmitted vertically as viral particles from parent to offspring. Recent studies refer to these viruses as endosymbionts given their intimate relationships with their hosts (Longdon and Jiggins 2012, Roossinck 2015). Viruses are extremely diverse and prevalent but, since the advent of virology with the discovery of the Tobacco mosaic virus in 1886 (Mayer et al. 1942), they have mostly been considered as causative agents of diseases (but see(Roossinck and Bazán 2017). Nevertheless, their effect on host fitness can vary widely and range from mutualism (i.e. the host derives a fitness benefit) to parasitism (i.e. the host suffers a fitness decline) (Xu et al. 2008, Roossinck 2015). A recent meta-analysis conducted by Flick et al. (2016), including 50 studies, showed that natural enemies can avoid pathogen-infected prey and if not, predators and parasitoids consuming these prey can have reduced fecundity, survival and longevity. However, most of these studies excluded viruses that do not regularly kill their hosts and it remains unclear if non-lethal viruses can modulate interactions between virus-infected prey and natural enemies. For instance, viral endosymbionts could modify the structure of the prey populations (e.g. proportion of adults relative to juvenile), which, in turn, could influence the impact of natural enemies on prey population dynamics. Given that viral endosymbionts often decrease both quality and abundance of their hosts (Van Munster et al. 2003a, b), we hypothesised that parasitism and predation rates would be weaker on infected hosts compared to uninfected ones. Alternatively, infection with microbes may alter host defensive behaviours (Dion et al. 2011, Polin et al. 2014) so that infected hosts may be more affected by natural enemies. Overall, the influence of the virus on trophic interactions may likely depend on the balance between virus effects on both host phenotypes and host demography.

Here, we investigated the role of a viral endosymbiont on trophic interactions within aphid-based food webs. Aphids can host densoviruses that are non-enveloped singlestranded DNA viruses (Tijssen et al. 2016). In the green peach aphid, Myzus persicae Sulzer (Hemiptera: Aphididae), the M. persicae densovirus (MpDNV hereafter) negatively impacts aphid growth and fecundity without being lethal (Van Munster et al. $2003 \mathrm{a}, \mathrm{b})$. The MpDNV is vertically transmitted to the progeny at a rate of $40 \%$ but is also efficiently propagated in the aphid colony through the plant vasculature (horizontal transmission) resulting in all individuals being infected in laboratory conditions (Van Munster et al. 2003a, b). Interestingly, the MpDNV is highly prevalent in French crops with more than $94 \%$ of aphid populations being infected (Brault et al. in prep.). This high MpDNV prevalence suggests that it could play an important role for aphid populations and interactions with upper (i.e., natural enemies) and lower trophic levels (i.e. aphid host plants). As the MpDNV infection reduces aphid growth and fecundity (Van Munster et al. 2003a, b), we hypothesised that both parasitoids and predators would be more reluctant at attacking these low-quality prey. However, if the MpDNV infection alters aphid defensive behaviours then virus-infected individuals would be most accessible prey. To test these hypotheses, we measured the effect of MpDNV infection on aphids' ecology at three organization levels: the individual, the population, 
and the community. At the individual level, we analysed the effects of MpDNV infection on aphids' quality as prey by measuring their weight (i.e. the amount of nutrients for enemies) and defensive behaviours. At the population level, we tested the influence of MpDNV infection on aphid population density and population structure (i.e. proportion of adults and nymphs). At the community level, we measured the effects of MpDNV infection on aphid susceptibility towards strict predators and parasitoids. Overall, our study showed that MpDNV infection could affect trophic interactions by modulating aphid traits, population demography and susceptibility toward natural enemies.

\section{Materials and methods}

\section{Biological materials}

Myzus persicae were maintained on plants of the sweet pepper Capsicum annuum (Solanales: Solanaceae) cv. Lamuyo F1. The natural enemies used in the study were the predatory Harlequin ladybeetle Harmonia axyridis Pallas (Coleoptera: Coccinellidae) and the two parasitoid species Aphidius matricariae Haliday and Aphidius ervi Haliday (Hymenoptera: Aphidinae). These two parasitoids parasitize $M$. persicae on sweet pepper crops in greenhouses (Gavkare et al. 2014) and the ladybeetle H. axyridis is often used to control M. persicae populations (De Clercq et al. 2003).

Two lineages of a single aphid clone of M. persicae Sulzer (Hemiptera: Aphididae) originated from Colmar (France) and designated as the Colmar clone were used. One aphid lineage was infected with the Myzus persicae densovirus (MpDNV) while the other was cured of MpDNV (Clavijo et al. 2016). The presence/absence of MpDNV in both aphid lineages was checked by a specific Polymerase Chain Reaction (PCR) (Clavijo et al. 2016) at the beginning and the end of all experiments. Both aphid lineages were maintained at low population density (i.e. less than 60 adults per plant) on sweet pepper host plants grown from seeds $($ Voltz@) in nylon cages $(30 \times 30 \times 30 \mathrm{~cm})$ for 2 months before the experiments. To avoid confounding effects of aphid age or developmental stage, third-instar larvae or two-day-old adult $M$. persicae females obtained from synchronous cohorts were used in experiments (see below for more details).

Approximately $200 \mathrm{H}$. axyridis adults were collected in October 2015 on the campus of the Ecole Nationale Supérieure de Formation de l'Enseignement Agricole (AuzevilleTolosane, France). Adult ladybeetles were then reared in 5-L plastic boxes at $20^{\circ} \mathrm{C}$ and fed three times a week with pollen and an excess of pea aphids (Acyrthosiphon pisum Harris; Hemiptera: Aphididae). Pea aphids were reared on broad bean Vicia faba L. cv. Aquadulce. A piece of corrugated filter paper was added to each plastic boxes to provide a suitable substrate for oviposition. Ladybeetle eggs were collected three times a week and neonate larvae were reared in $175-\mathrm{cm}^{3}$ plastic boxes and fed with pea aphids until they reach the second larval instar at which they were used for the experiments. A. matricariae and A. ervi parasitoid mummies (i.e., dead aphids each containing a single parasitoid pupae) were purchased from Koppert Biological Systems@ $\odot$. After their emergence, parasitoid females were isolated from aphid mummies and enclosed singly in plastic tubes $(22 \times 1 \mathrm{~cm})$ containing moistened cotton, a diluted drop of honey and one male for mating. In all experiments, only 1-5 days old parasitoid females were used. Just prior to the experimental test, females were allowed to oviposit in one-third-instar aphid larva (infected or not according to the experimental treatment). This allowed the parasitoid female to gain experience in aphid handling and to reduce the possibility of 
any behavioural traits associated with first host attacks that might affect wasp's parasitism efficiency. Each parasitoid female was used only once in the experiments. Insect rearing, plant culture and experiments were all performed in controlled conditions at $20^{\circ} \mathrm{C}, 70 \pm 10 \%$ relative humidity, and $16 \mathrm{~L}: 8 \mathrm{D}$ photoperiod. These experimental conditions mimic summer conditions during which $M$. persicae only reproduces by parthenogenesis.

\section{MpDNV infection and aphids' quality as prey}

To test the effect of MpDNV infection on aphids' quality as prey, we measured both aphid body mass and aphid defensive behaviours according to their MpDNV infection status. For each infection status (i.e. infected or not infected by MpDNV), twenty-five adult $M$. persicae females obtained from synchronous cohorts were individually weighed to the nearest $0.1 \mu \mathrm{g}$ using a microbalance (SC2, Sartorius@). For the aphid behavioural defences study, A. matricariae parasitoids were used as natural enemies. A female parasitoid was transferred to a glass Petri dish $(3.5 \mathrm{~cm}$ in diameter) containing 15 third-instar $M$. persicae larvae from a given lineage (infected or not by MpDNV) feeding on a disc of sweet pepper leaf lining the bottom of the dish. Behavioural observations began when the parasitoid wasp attacked the first aphid and ended when ten aphids were attacked. When the parasitoid stopped searching after both locating and contacting (i.e. displaying antennal tapping on aphid host and/or inserting ovipositor in the aphid's body), the event was classified as an encounter by the parasitoid wasp. The following aphid behaviours were recorded during the trials: kicking and shaking the body (i.e., aggressive defensive behaviours), walking or running away (i.e., escape behaviour) and emitting cornicle secretions containing alarm pheromone (i.e., collective defence). The outcome of an encounter was also recorded: aphid acceptance for oviposition or its rejection by the parasitoid. Piercing the aphid cuticle with the ovipositor was scored as an acceptance while any attack by a parasitoid that did not lead to a stabbing behaviour was scored as a rejection. Rejection events can be associated with either aphid defensive behaviours or parasitoid females' foraging decision (i.e., rejection of passive aphid individuals due to their quality). During our experiments, all encountered aphids were attacked by the females and the rejection events observed were associated with the behavioural defences of aphids only. For each aphid lineage (i.e. infected or not by MpDNV), ten experimental replicates (i.e. 100 aphid individuals attacked per lineage) were performed.

\section{MpDNV infection, aphid population properties and predation susceptibility}

A full factorial experiment was conducted to investigate the effects of the MpDNV infection (i.e., presence vs. absence) and predation by predatory ladybeetle (i.e., presence vs. absence) on various aphid population properties: total aphid density, number of nymphs, proportion of adult aphids and adult survival. For the experiment, 36-days-old sweet pepper plants with 4 unfurled leaves and two cotyledons were individually placed in $500 \mathrm{~mL}$ plastic pots containing $400 \mathrm{~mL}$ of fertilized soil substrate (®Jiffy substrates NFU 44-551). Fifty parthenogenetic adult females of $M$. persicae obtained from synchronous cohorts from a given lineage (infected or not by MpDNV) were then transferred on the first leaf of each plant using a fine paintbrush. Eighteen replicates of each treatment were performed, leading to 72 samples (i.e. 72 sweet pepper plants) (4 treatments $\times 18$ replicates). For technical reason, not all replicates were conducted simultaneously, and the samples were collected from three independent experiments performed in similar conditions. After the aphid introduction, plants were

'This article is protected by copyright. All rights reserved.' 
enclosed in transparent plastic cylinders (Diameter: $14 \mathrm{~cm}$; high: $29 \mathrm{~cm}$ ). The top of the cylinder and the two lateral openings were covered with mesh muslin for ventilation. One hour later, allowing aphid settlement, a single $H$. axyridis second-instar ladybeetle larva was introduced at the bottom of the plant in each experimental cylinder of the predation treatment. Ladybird larvae were not fed 24 hours prior to prevent satiated predators from being used in the experiment. Twenty-four hours after predator introduction, the ladybeetle larvae were collected and the number of adults and newborn aphids (i.e. larvae) were counted.

\section{MpDNV infection and parasitism susceptibility}

Both parasitoid species, A. matricariae and A. ervi, were used to evaluate the aphid susceptibility to parasitism depending on their viral infection status. The experiment started with the introduction of a single parasitoid female in a glass Petri dish $(3.5 \mathrm{~cm}$ in diameter) containing 15 third-instar $M$. persicae larvae from a given lineage (infected or not by MpDNV) feeding on a disc of sweet pepper leaf lining the bottom of the dish. Aphids were carefully removed from the arena once stung by a parasitoid wasp to prevent multiple stings on a single individual. A parasitoid sting corresponds to an ovipositor insertion, which leads to a single egg injection into the aphid's body (McBrien and Mackauer 1990). The experiment ended when 10 aphids were stung by the parasitic wasp. The stung aphids were then transferred onto a 36-days-old sweet pepper host plant. Twenty days later, stung aphids were inspected to determine whether they developed into mummies. The proportion of mummification was calculated by dividing the number of aphid mummies by the total number of stung aphids. In addition, a round hole on the mummies was an indication of an adult parasitoid emergence and the proportion of parasitoid emergence (i.e. the number emergences divided by the number of mummies) was calculated. For each aphid lineage, ten experimental replicates were performed with each parasitoid species leading to about 400 stung aphids (i.e., about 100 aphid individuals stung per lineage and per parasitoid species).

\section{Statistical analyses}

All analyses were computed using R v. 3.4.2 (R Development Core Team 2017). The effect of the MpDNV infection on the aphid body mass was analysed using a Student's t-test. We used a series of Binomial GLMMs (Generalized Linear Mixed Models) to test the effect of the MpDNV infection on (1) the proportion of aphids exhibiting aggressive behaviours (i.e., kicking and/or shaking the body), or escaping, or emitting alarm pheromone when attacked by $A$. matricariae female (one model for each response variable) and (2) the proportion of parasitoid attacks that aborted due to aphids' behavioural defence. Binomial GLMMs were used to test the effects of the MpDNV infection status (presence/absence), the parasitoid species (A. ervi/A. matricariae), and their interaction on both the proportion of mummification and the proportion of parasitoid emergence from aphid mummies (one model for each response variable). As several aphids were exposed to the same parasitoid female, parasitoid identity was considered as a random factor in all these Binomial GLMMs in order to include data substructure.

We used a series of GLMMs with experimental date as a random effect to test the effects of the MpDNV infection status, the predator treatment (presence/absence), and their interaction on (1) both aphid (adults and nymphs) population density (i.e. number of aphids per plant) and aphid nymph density and (2) on both the proportion of adult aphids and the adult aphid survival (i.e. the proportion of adult aphids found alive at the 
end of the experiment). We used Poisson and Binomial errors for the densities and the proportions, respectively. Overdispersion in GLMMs was tested using the blmeco package that computes the estimated scale in a GLMM (Korner-Nievergelt et al. 2015). No case of overdispersion was detected. We did not take into account possible correlations among the three response variables as we are not aware of a statistical analysis that would allow testing the effects of multiple explanatory variables (and their interactions) on multiple response variables (with different distribution families) and that would also take into account random effects. GLMMs were computed using the lme4 package (Bates et al. 2015).

\section{Results}

\section{MpDNV infection and aphids' quality as prey}

Contrary to our predictions, MpDNV did not impact the quality of aphids as prey with the exception of prey body mass. The MpDNV infection significantly reduced aphid body mass $(\mathrm{t}=4.03, \mathrm{df}=45, \mathrm{P}=0.002)$ : the infected aphids were $38 \%$ lighter than uninfected ones. The mean ( \pm s.e.) body mass of infected aphids was $0.203 \pm 0.019 \mu \mathrm{g}$ while the mass of uninfected ones was $0.329 \pm 0.025 \mu \mathrm{g}$. Our behavioural experiments showed that aphid MpDNV infection status did not influence the propensity of aphids to exhibit aggressiveness $\left(\chi^{2}=1.341, \mathrm{df}=1, \mathrm{P}=0.246\right.$, Fig. 1a), escape behaviours $\left(\chi^{2}=\right.$ $0.064, \mathrm{df}=1, \mathrm{P}=0.799$, Fig. $1 \mathrm{~b})$ and alarm pheromone emission $\left(\chi^{2}=0.028, \mathrm{df}=1, \mathrm{P}\right.$ $=0.865$, Fig. 1c) when attacked by $A$. matricariae parasitoid. Moreover, the proportion of parasitoid attacks that aborted due to aphid defensive behaviours did not vary according to their infection status $\left(\chi^{2}=0.702, \mathrm{df}=1, \mathrm{P}=0.402\right.$, Fig. 1d).

\section{MpDNV infection, predation susceptibility and aphid population properties}

Accordingly to our predictions, our results showed that the infection with MpDNV modified the effects of predators on aphid demography. The MpDNV infection influenced the aphid population density (i.e. the number of adults and nymphs per plant) but this effect varied according to presence of predators (Table 1, Fig. 2a). While both viral infection and presence of predators induced a decline in aphid population density, the detrimental effect of predation on density was weaker in infected populations compared to uninfected ones (32 vs. 37\%). Similar results were found for the density of aphid nymphs: the viral infection effect on this population property varied according to presence of predators (Table 1, Fig. 2b). Predators reduced the density of infected nymphs by $31 \%$ whereas they reduced the density of uninfected nymphs by $41 \%$. Both MpDNV infection and presence of predators had negative effect on the adult aphid survival (Table 1, Fig. 2c). Adult survival decreased by $4 \%$ when infected with MpDNV and presence of predators led to a survival reduction of about $30 \%$ regardless to the aphid infection status (Table 1, Fig. 2c). Finally, the proportion of adults in aphid population was affected by the MpDNV infection but this effect varied according to the presence of predators (Table 1, Fig. 2d). Predators increased the proportion of adults in MpDNV non-infected populations only.

\section{MpDNV infection and parasitism susceptibility}

Interestingly, our experiments showed that infected aphids were more susceptible to their parasitoids. Once stung by a parasitoid female, the proportion of mummified 
aphids significantly varied between both parasitoid species: mummification was higher with A. matricariae than with A. ervi $\left(\chi^{2}=23.845\right.$, df $=1, \mathrm{P}<0.001$; Fig. 3a).

Moreover, mummification was higher when aphids were infected with the MpDNV $\left(\chi^{2}\right.$ $=5.789, \mathrm{df}=1, \mathrm{P}=0.016$ ), independently of the parasitoid species (interaction parasitoid species $\times$ MpDNV: $\chi^{2}=0.094, \mathrm{df}=1, \mathrm{P}=0.758$; Fig. 3a). Overall, mummification increased by a factor of 1.5 in MpDNV infected aphids. In addition, the proportion of parasitoid emergence from aphid mummies did not differ between parasitoid species $\left(\chi^{2}=3.249, \mathrm{df}=1, \mathrm{P}=0.071\right.$; Fig. $\left.3 \mathrm{~b}\right)$ and was not affected by the MpDNV infection $\left(\chi^{2}=1.641, \mathrm{df}=1, \mathrm{P}=0.200\right.$; Fig. $\left.3 \mathrm{~b}\right)$.

\section{Discussion}

Most previous studies focused on effects of insect viral endosymbionts on trophic interactions concerned lethal pathogens (Jiang et al. 2011, Flick et al. 2016) and implied a single natural enemy. Moreover, we lack information on the mechanisms explaining why the impact of natural enemies on prey population density would differ depending on the viral infection status. Our results showed that the infection of $M$. persicae by the MpDNV induced various detrimental effects on aphid individuals and populations: it declines aphid body mass and population density. Although MpDNV infection did not influence the aphid defensive behaviours toward parasitoids, it did enhance parasitism susceptibility by increasing the proportion of successful mummifications. In line with our hypothesis, we found that the MpDNV infection decreased the impact of predator on population density. Overall, the impacts of the MpDNV infection depended on the natural enemies considered with a positive effect on parasitism and a negative effect on predation.

As reported by Van Munster et al. (2003a) we found that aphids MpDNV-infected were lighter than uninfected ones. Van Munster et al. (2003) used a different aphid clone suggesting that these effects could be generalized to multiple aphid genotypes. Body mass is strongly related to aphid fecundity and former studies have reported that the smaller aphids infected by MpDNV reproduce less than the uninfected larger ones which could represent a physiological cost of viral infection (Van Munster et al. 2003a). We thus hypothesised that this effect of MpDNV infection on aphid life-history traits may thus have effects at the population scale. Our results showed that MpDNV infection reduces the survival of adult aphids as well as both the density and the proportion of aphid nymphs within populations. These demographic effects of MpDNV infection can have important consequences on aphid populations' dynamics as well as on interactions with upper trophic levels.

Due to their lower body mass, infected aphids present a deficit in nutritional value for enemies as reported in other biological systems (Flick et al. 2016). In parasitoids, smaller aphids can be identified as low-quality hosts and influence parasitoid foraging behaviours, leading to indirect effects on parasitoid populations (Monticelli et al. 2019). Overall, body mass is a master trait that determines the abundance, growth rate and trophic position of many organisms (Gillooly et al. 2002, Cohen et al. 2003, Brown et al. 2004, Savage et al. 2004) and by modifying this trait, viruses may have important consequences on consumer fitness (Flick et al. 2016) and dynamics and structure of food webs (Sentis et al. 2017).

In the pea aphid, Acyrthosiphon pisum, infection with the bacterial endosymbiont

Hamiltonella defensa induces reduction in aphid defensive behaviours (Dion et al. 2011, Polin et al. 2014) and by consequence, increases in predation rates (Polin et al. 2014). Altered behaviours were also observed in aphids infected with entomopathogenic fungi (Jensen et al. 2001) and plant viruses acquired from infected host plants (Mauck et al. 
2018). As viral infection can be associated with physiological costs for aphids, this may induce some reductions in aphid defensive behaviours (Dion et al., 2010). Here MpDNV infection did not influence aphid behavioural defences once attacked by parasitoid nor the proportion of aborted attacks due to aphid behavioural defences. In other words, the MpDNV infection did not influence the likelihood of being stung by a parasitoid. However, once a parasitoid egg was inserted into the aphid's body, the MpDNV infection influenced the parasitoid larval development positively: the proportion of mummified aphids was higher in MpDNV-infected aphids, independent of the parasitoid species. This result can be explained by two non-exclusive hypotheses. First, a reduction in immune defence associated with viral infection would enhance parasitism rate. Manipulation of insect immunity by viruses has been shown in insects (Kroemer and Webb 2004) and may benefit parasitoids (Bouletreau and Fleury 2005). By reducing body mass, viral infection may also decline resource allocation to immunity. Secondly, MpDNV infection may enhance susceptibility of aphids to components injected by parasitoids during oviposition (e.g. cocktail of venoms that could manipulate aphid physiology, development and immunity,(Digilio et al. 2000). Whatever the underlying mechanisms of the ecological cost associated with MpDNV infection, our results showed that the viral infection increased parasitism rate for both parasitoid species.

We found that both the virus and the ladybeetle predator decreased aphid population density. However, their effects were not additive as the impact of ladybirds on aphid population density was weaker for infected aphids compared to uninfected ones.

Ladybeetle predators strongly decreased the number of aphid nymphs, especially for uninfected ones compared to infected ones but predation rate on adult aphids was not influenced by the viral infection. The stronger predation on uninfected nymphs also explains why predators increased the proportion of adult aphids in uninfected populations but not in infected ones. We thus conclude that the combined effects of the viral infection and the predator on aphid density are not additive and depend on aphid developmental instar which highlights the importance of taking into account population structure when assessing the ecological consequences on the viral infection. The mechanisms underlying these results remain to be investigated in more details, but it is possible that both biotic stresses (MpDNV infection and ladybeetle) share aphid physiological defence responses and, consequently do not result in additive effects. This hypothesis is in agreement with a previous study by Sentis et al. (2013) in which $M$. persicae exposed to an abiotic stress (heat waves) were less impacted by ladybeetles than aphids non-exposed to heat waves. The mechanism sustaining these results needs further investigation, but our results indicate that, although the MpDNV infection decreased the predator effect on aphid density, it did not increase aphid survival under predation. We thus conclude that, as hypothesized, the MpDNV virus mitigates the effects of the ladybeetle predator.

Our results evidenced sub-lethal effects of MpDNV infection on aphid fitness. These physiological and ecological costs associated with MpDNV infection could limit viral propagation in host populations as they reduce aphid population density and aphid survival. Interestingly, that is in contradiction with the high prevalence of the virus observed in nature (Brault et al. in prep). The evolutionary dynamics of MpDNV is thus questioned here. First, it may be hypothesized that MpDNV infection would provide some benefits to infected aphids towards abiotic or biotic factors not tested here. For instance, Xu et al. (2014) found that Helicoverpa armigera densovirus-1 (HaDNV) can enhance the resistance of Lepidoptera larvae against another virus $(H$. armigera nucleopolyhedrovirus) that has lethal consequences. In addition to potential beneficial 
effects of MpDNV infection, high prevalence could be explained by transmission routes of viruses. For microbial endosymbionts, transmission mode is often mixed, involving both vertical and horizontal transfers from either the environment or host switching (Ferrari and Vavre 2011). For instance, Van Munster et al. (2005) showed that the aphid's host plant can transport MpDNV particles, without viral replication, from infected aphids to uninfected ones via the phloem. This horizontal route can complement vertical transmission rate to end up with all individuals being infected within a M. persicae colony (Van Munster et al. 2003a). Further studies on both virusmediated phenotypes and host switching transfers are needed to understand MpDNV epidemiology.

\section{Conclusion}

By reducing both aphid nutritional quality and availability, increasing their susceptibility to parasitism, and modulating the predator effect on aphid population's growth rate, our study highlighted that viral endosymbionts can be prevalent drivers of their host ecology as well as their interactions with natural enemies. Interestingly, the influence of the virus on trophic interactions depended on the natural enemies as it increased parasitism rate and decreased predation rate. These virus-mediated ecological effects may have consequences on upper (i.e., natural enemies) and lower trophic levels (i.e. aphid host plants). As hidden players in evolutionary ecology of insects, viral endosymbionts require further attention to better understand their dynamics and ecological consequences in nature.

\section{Data availability statement}

Data are available from the Dryad Digital Repository: <https://dx.doi.orgh/105061/dryad.xxxxxxx> (Dupont et al. 2019).

Acknowledgements - Funding - This work was supported by the French 'Ministère de l'Enseignement Supérieur et de la Recherche' and the ANR funded French Laboratory of Excellence projects 'LABEX TULIP' and 'LABEX CEBA' (ANR10-LABX-41, ANR-10-LABX-25-01) and the ANR funded Toulouse Initiative of Excellence "IDEX UNITI" (ANR11-IDEX-0002-02). AS was also funded by the

People Program (Marie Curie Actions) of the European Union's Seventh Framework Program (FP7/2007-2013) under REA grant agreement $n^{\circ}$ PCOFUNDGA-2013-609102, through the PRESTIGE program coordinated by Campus France.

Author contributions - A. Michiels, A. Sentis and C. Dupont contributed equally to this paper

\section{References}

Bates, D., M. Mächler, B. Bolker, and S. Walker. 2015. Fitting linear mixed-effects models using lme4. Journal of Statistical Software 67:1-48. 
Bouletreau, M., and F. Fleury. 2005. Parasitoid insects and their prokaryotic helpers: gifted parasites? Bulletin societe zoologique de France 130:177.

Brown, J. H., J. F. Gillooly, A. P. Allen, V. M. Savage, and G. B. West. 2004. Toward a metabolic theory of ecology. Ecology 85:1771-1789.

Clavijo, G., M. van Munster, B. Monsion, N. Bochet, and V. Brault. 2016. Transcription of densovirus endogenous sequences in the Myzus persicae genome. Journal of General Virology 97:1000-1009.

Cohen, J. E., T. Jonsson, and S. R. Carpenter. 2003. Ecological community description using the food web, species abundance, and body size. Proceedings of the National Academy of Sciences 100:1781-1786.

De Clercq, P., I. Peeters, G. Vergauwe, and O. Thas. 2003. Interaction between Podisus maculiventris and Harmonia axyridis two predators used in augmentative biological control in greenhouse crops. BioControl 48:39-55.

Dicke, M. 2009. Behavioural and community ecology of plants that cry for help. Plant, Cell \& Environment 32:654-665.

Digilio, M. C., N. Isidoro, E. Tremblay, and F. Pennacchio. 2000. Host castration by Aphidius ervi venom proteins. Journal of Insect Physiology 46:1041-1050.

Dion, E., S. E. Polin, J.-C. Simon, and Y. Outreman. 2011. Symbiont infection affects aphid defensive behaviours. Biology Letters 7:743-746.

Dupont, C. et al. 2019. Virus mediated trophic interactions between aphids and their natural enemies

Ferrari, J., and F. Vavre. 2011. Bacterial symbionts in insects or the story of communities affecting communities. Philosophical Transactions of the Royal Society B: Biological Sciences 366:1389-1400. 
Flick, A. J., M. A. Acevedo, and B. D. Elderd. 2016. The negative effects of pathogeninfected prey on predators: a meta-analysis. Oikos 125:1554-1560.

Frago, E., M. Dicke, and H. C. J. Godfray. 2012. Insect symbionts as hidden players in insect-plant interactions. Trends in Ecology \& Evolution 27:705-711.

Gavkare, O., S. Kumar, and G. Japoshvili. 2014. Effectiveness of native parasitoids of Myzus persicae in greenhouse environments in India. Phytoparasitica 42:141144.

Gillooly, J. F., E. L. Charnov, G. B. West, V. M. Savage, and J. H. Brown. 2002. Effects of size and temperature on developmental time. Nature 417:70-73.

Girling, R., M. Hassall, J. Turner, and G. Poppy. 2006. Behavioural responses of the aphid parasitoid Diaeretiella rapae to volatiles from Arabidopsis thaliana induced by Myzus persicae. Entomologia Experimentalis et Applicata 120:1-9.

Godfray, H. C. J. 1994. Parasitoids: behavioral and evolutionary ecology. Princeton University Press.

Hrček, J., A. H. C. McLean, and H. C. J. Godfray. 2016. Symbionts modify interactions between insects and natural enemies in the field. Journal of Animal Ecology 85:1605-1612.

Jensen, M., J. Losey, and A. Hajek. 2001. Altered behavior and distribution of pea aphids, Acyrthosiphon pisum (Homoptera: Aphididae), infected with Pandora neoaphidis (Zygomycetes: Entomophthorales). BioControl 46:337-343.

Jiang, J., A. Zeng, X. Ji, N. Wan, and X. Chen. 2011. Combined effect of nucleopolyhedrovirus and Microplitis pallidipes for the control of the beet armyworm, Spodoptera exigua. Pest Management Science 67:705-713.

Kooi, B. W., L. D. J. Kuijper, and S. A. L. M. Kooijman. 2004. Consequences of symbiosis for food web dynamics. Journal of Mathematical Biology 49:227-271. 
Korner-Nievergelt, F., T. Roth, S. Von Felten, J. Guélat, B. Almasi, and P. KornerNievergelt. 2015. Bayesian data analysis in ecology using linear models with R, BUGS, and Stan. Elsevier Academic Press, Oxford, UK.

Kroemer, J. A., and B. A. Webb. 2004. Polydnavirus genes and genomes: emerging gene families and new insights into polydnavirus replication. Annual Reviews in Entomology 49:431-456.

Longdon, B., and F. M. Jiggins. 2012. Vertically transmitted viral endosymbionts of insects: do sigma viruses walk alone? Proceedings of the Royal Society B: Biological Sciences 279:3889-3898.

Mauck, K. E., Q. Chesnais, and L. R. Shapiro. 2018. Chapter Seven - Evolutionary Determinants of Host and Vector Manipulation by Plant Viruses. Pages 189-250 in C. M. Malmstrom, editor. Advances in Virus Research. Academic Press.

Mayer, A., J. Johnson, D. I. Ivanovskiū, M. W. Beijerinck, and E. Baur. 1942. Concerning the mosaic disease of tobacco. American Phytopathological Society 1:1-62.

McBrien, H., and M. Mackauer. 1990. Heterospecific larval competition and host discrimination in two species of aphid parasitoids: Aphidius ervi and Aphidius smithi. Entomologia Experimentalis et Applicata 56:145-153.

McFall-Ngai, M., M. G. Hadfield, T. C. Bosch, H. V. Carey, T. Domazet-Lošo, A. E. Douglas, N. Dubilier, G. Eberl, T. Fukami, and S. F. Gilbert. 2013. Animals in a bacterial world, a new imperative for the life sciences. Proceedings of the National Academy of Sciences 110:3229-3236.

McLean, A. H. 2019. Cascading effects of defensive endosymbionts. Current Opinion in Insect Science 32:42-46. 
McLean, A. H., B. J. Parker, J. Hrček, L. M. Henry, and H. C. J. Godfray. 2016. Insect symbionts in food webs. Phil. Trans. R. Soc. B 371:20150325.

Monticelli, L. S., Y. Outreman, E. Frago, and N. Desneux. 2019. Impact of host endosymbionts on parasitoid host range-From mechanisms to communities. Current Opinion in Insect Science 32:77-82.

Montllor, C. B., A. Maxmen, and A. H. Purcell. 2002. Facultative bacterial endosymbionts benefit pea aphids Acyrthosiphon pisum under heat stress. Ecological Entomology 27:189-195.

Oliver, K. M., A. H. Smith, and J. A. Russell. 2014. Defensive symbiosis in the real world-advancing ecological studies of heritable, protective bacteria in aphids and beyond. Functional Ecology 28:341-355.

Polin, S., J.-C. Simon, and Y. Outreman. 2014. An ecological cost associated with protective symbionts of aphids. Ecology and Evolution 4:836-840.

R Development Core Team. 2017. R: a language and environment for statistical computing, R Foundation for Statistical Computing, Vienna, Austria.

Roossinck, M. J. 2015. Move over, bacteria! Viruses make their mark as mutualistic microbial symbionts. Journal of Virology 89:6532-6535.

Roossinck, M. J., and E. R. Bazán. 2017. Symbiosis: viruses as intimate partners. Annual review of virology 4:123-139.

Savage, V. M., J. F. Gillooly, J. H. Brown, G. B. West, and E. Charnov. 2004. Effects of body size and temperature on population growth. The American Naturalist 163:429-441.

Sentis, A., A. Binzer, and D. S. Boukal. 2017. Temperature-size responses alter food chain persistence across environmental gradients. Ecology Letters 20:852-862. 
Sentis, A., J. L. Hemptinne, and J. Brodeur. 2013. Effects of simulated heat waves on an experimental plant-herbivore-predator food chain. Global Change Biology 19:833-842.

Simon, J.-C., S. Boutin, T. Tsuchida, R. Koga, J.-F. Le Gallic, A. Frantz, Y. Outreman, and T. Fukatsu. 2011. Facultative symbiont infections affect aphid reproduction. PLoS ONE 6:e21831.

Tijssen, P., J. J. Pénzes, Q. Yu, H. T. Pham, and M. Bergoin. 2016. Diversity of small, single-stranded DNA viruses of invertebrates and their chaotic evolutionary past. Journal of Invertebrate Pathology 140:83-96.

Tsuchida, T., R. Koga, and T. Fukatsu. 2004. Host plant specialization governed by facultative symbiont. Science 303:1989-1989.

Tsuchida, T., R. Koga, M. Horikawa, T. Tsunoda, T. Maoka, S. Matsumoto, J.-C. Simon, and T. Fukatsu. 2010. Symbiotic bacterium modifies aphid body color. Science 330:1102-1104.

Van Munster, M., A. Dullemans, M. Verbeek, J. van den Heuvel, C. Reinbold, V. Brault, A. Clerivet, and F. van der Wilk. 2003a. Characterization of a new densovirus infecting the green peach aphid Myzus persicae. Journal of Invertebrate Pathology 84:6-14.

Van Munster, M., A. Dullemans, M. Verbeek, J. van den Heuvel, C. Reinbold, V. Brault, A. Clerivet, and F. Van der Wilk. 2003b. A new virus infecting Myzus persicae has a genome organization similar to the species of the genus DensovirusFN1. Journal of General Virology 84:165-172.

Wernegreen, J. J. 2012. Endosymbiosis. Current Biology 22:R555-R561.

Xu, P., F. Chen, J. P. Mannas, T. Feldman, L. W. Sumner, and M. J. Roossinck. 2008. Virus infection improves drought tolerance. New Phytologist 180:911-921. 
Xu, P., Y. Liu, R. I. Graham, K. Wilson, and K. Wu. 2014. Densovirus is a mutualistic symbiont of a global crop pest (Helicoverpa armigera) and protects against a baculovirus and Bt biopesticide. PLoS Pathogens 10:e1004490. 


\section{Figure Legends}

Figure 1. Behavioural defences of M. persicae when attacked by A. matricariae parasitoid in uninfected (left) and MpDNV-infected (right) aphid individuals: (a) proportion of individuals that exhibited aggressive behaviours when attacked; (b) proportion of individuals that escaped during attack; (c) proportion of individuals that emitted pheromone alarm during attack; (d) proportion of parasitoid attacks that aborted due to aphid behavioural defences. Statistical significance: NS (non-significant): $p$ > 0.05. The significance was tested using Chi-square test from analysis of deviance.

(a)
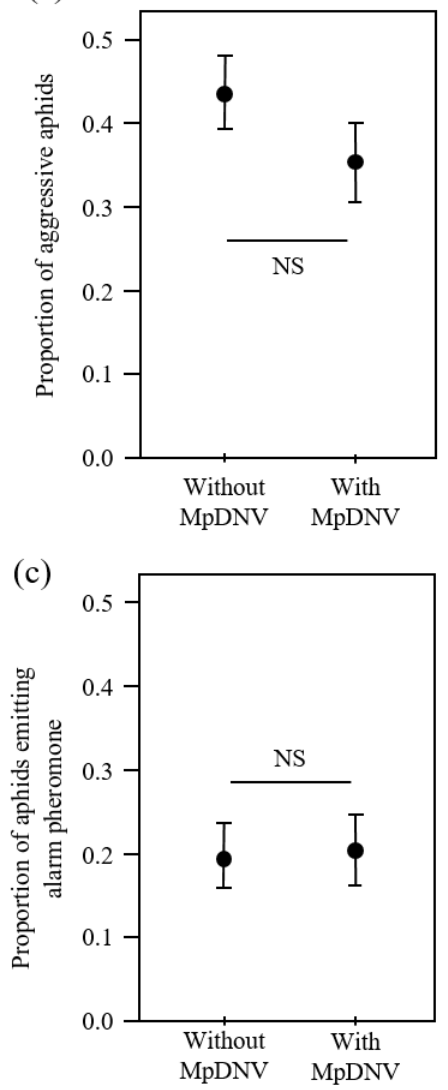

(b)
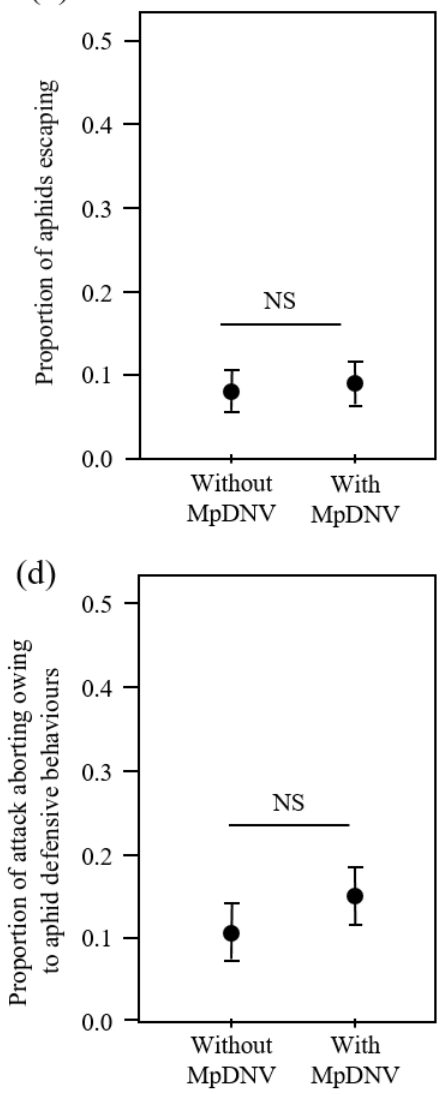

'This article is protected by copyright. All rights reserved.' 
Figure 2. Mean ( \pm SE) aphid population density (a), nymph aphid density (b), adult aphid survival (c), and adult aphid proportion (d) for MpDNV-infected aphids (red triangles) or uninfected ones (blue circles) in absence or presence of predators (x axis). Within each predation treatment, an asterisk denotes a significant $(\mathrm{P}<0.05)$ effect of MpDNV infection. Within each MpDNV treatment (i.e. within black circles or within grey triangles), different letters denote significant effects $(\mathrm{P}<0.05)$ of the predator. The significance was tested using a Chi-square test from analysis of deviance and post-hoc Tukey tests.
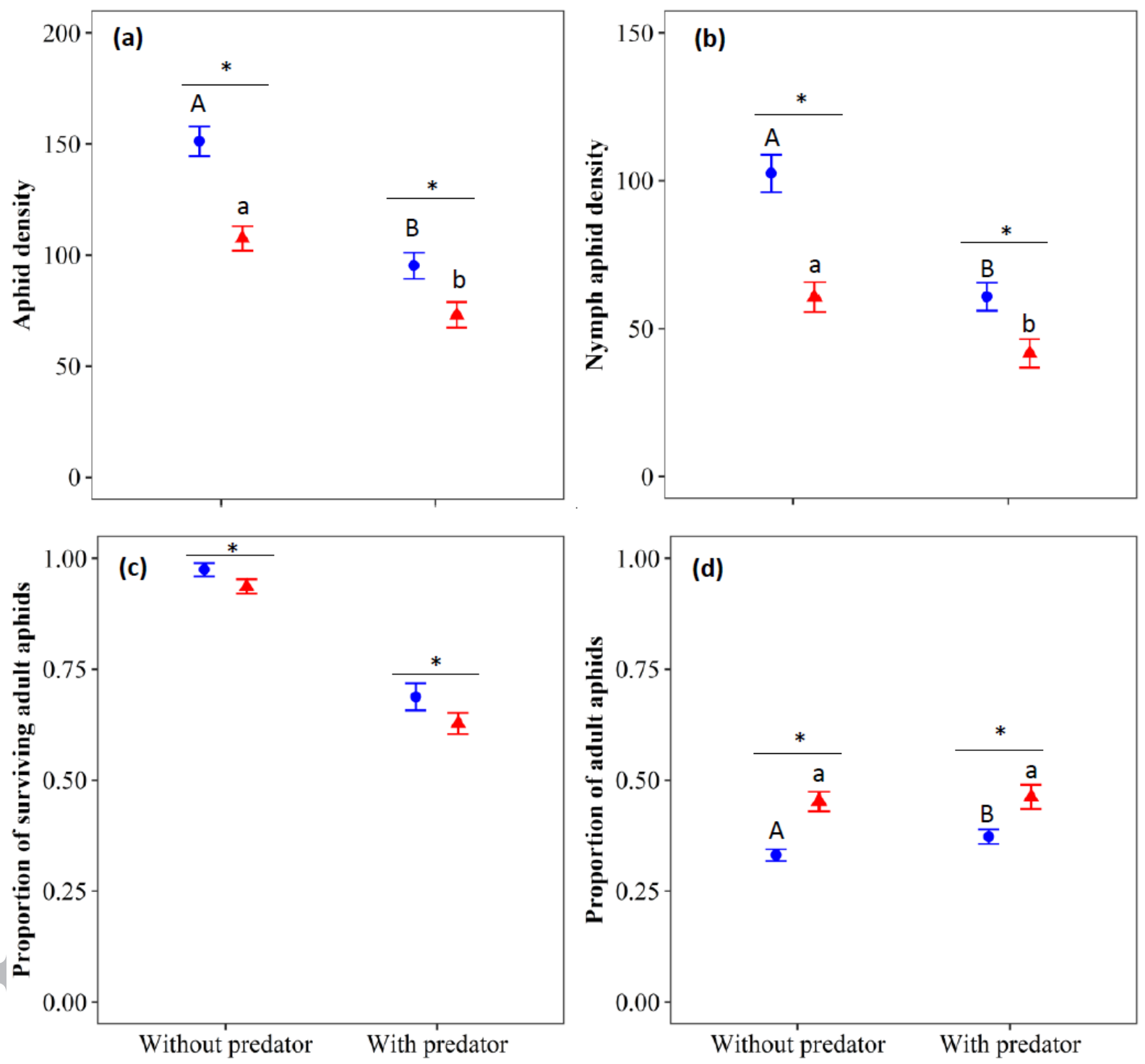

'This article is protected by copyright. All rights reserved.' 
Figure 3. Susceptibility of M. persicae to parasitism by A. ervi or A. matricariae in uninfected (blue circles) and MpDNV-infected (red triangles) aphid individuals: (a) proportion of mummified aphids (mean $\pm \mathrm{SE}$ ) and (b) proportion of parasitoid emergence (mean \pm SE). Statistical significance: $* * *: p<0.001$ and NS (nonsignificant): $p>0.05$. The significance was tested using Chi-square test from analysis of deviance.
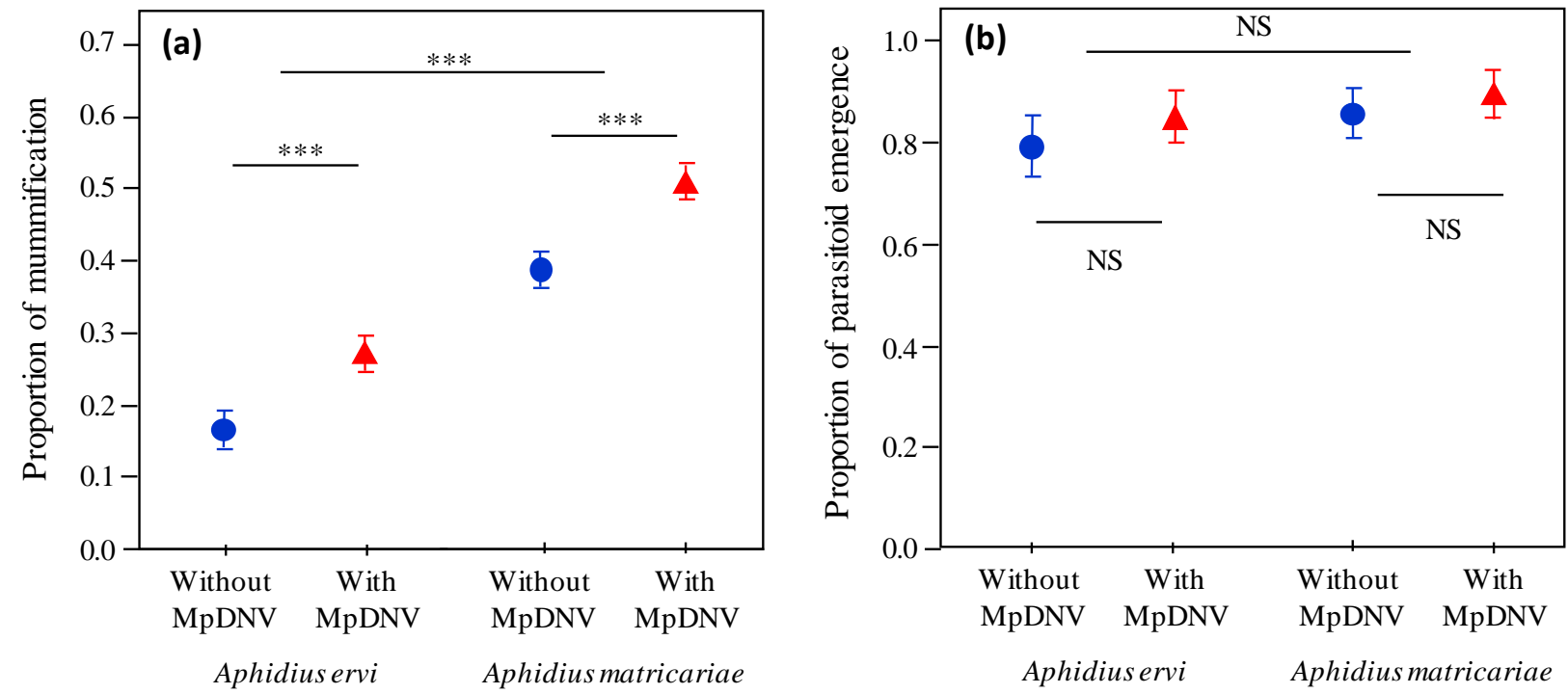

Aphidius ervi

Aphidius matricariae 


\section{Table Legend}

Table 1. Values of the $\chi^{2}$ statistics, degrees of freedom $(d f)$, and $p$ values of the GLMMs for the effects of MpDNV infection, predator presence, and their interactions on aphid population density, nymph aphid density, adult aphid survival, and the proportion of adult aphids.

\begin{tabular}{|c|c|c|c|c|c|c|c|c|}
\hline \multirow[b]{3}{*}{ Covariates } & \multicolumn{8}{|c|}{ Variables (distribution family) } \\
\hline & \multicolumn{2}{|c|}{$\begin{array}{l}\text { Aphid population } \\
\text { density (Poisson) }\end{array}$} & \multicolumn{2}{|c|}{$\begin{array}{l}\text { Nymph aphid } \\
\text { density (Poisson) }\end{array}$} & \multicolumn{2}{|c|}{$\begin{array}{l}\text { Adult aphid } \\
\text { survival (Binomial) }\end{array}$} & \multicolumn{2}{|c|}{$\begin{array}{l}\text { Proportion of adult } \\
\text { aphids (Binomial) }\end{array}$} \\
\hline & $\chi^{2}$ (d.f.) & $P$ - value & $\chi^{2}$ (d.f.) & $P$ - value & $\chi^{2}$ (d.f.) & $P$ - value & $\chi^{2}$ (d.f.) & $P$ - value \\
\hline MpDNV infection (1) & $183.85(1)$ & $<0.001$ & $248.85(1)$ & $<0.001$ & $11.62(1)$ & $<0.001$ & $77.15(1)$ & $<0.001$ \\
\hline Predator presence (2) & $320.35(1)$ & $<0.001$ & $235.34(1)$ & $<0.001$ & $312.90(1)$ & $<0.001$ & $3.79(1)$ & 0.052 \\
\hline Interaction $(1) *(2)$ & $3.96(1)$ & 0.047 & $7.60(1)$ & 0.006 & $2.26(1)$ & 0.132 & $4.12(1)$ & 0.047 \\
\hline
\end{tabular}

